\title{
Das teorias críticas às críticas das teorias: um estudo indiciário sobre a conformação dos debates no campo curricular no Brasil ${ }^{*}$
}

\author{
INÊS BARBOSA DE OLIVEIRA \\ Universidade do Estado do Rio de Janeiro, Rio de Janeiro, RJ, Brasil
}

MARIA LUIZA SÜSSEKIND

Universidade Federal do Estado do Rio de Janeiro, Rio de Janeiro, RJ, Brasil

\section{RESUMO}

O desenvolvimento do campo de estudos em Currículo no Brasil é marcado pela influência das teorias críticas que, mesmo quando deixam de ser majoritárias, permanece grande e talvez mesmo hegemônica, fazendo com que autores de outras tendências e matizes dialoguem com ela compulsoriamente, mesmo que de modo subliminar. Nossa hipótese de compreensão desse fenômeno vincula-se à importância intrínseca do debate para a constituição do campo do Currículo no país, considerando que as tendências pós-críticas hoje majoritárias são, elas mesmas, vinculadas a um pensamento progressista e de esquerda, a um projeto social emancipatório e democrático, ou seja, de certo modo emergiram, como as novas esquerdas, das teorias críticas e da esquerda tradicional. Procuramos, com isso, esboçar uma trajetória indiciária dessas teorias e os diálogos promovidos por/entre elas como elemento para a compreensão das tendências atuais no campo de estudos do Currículo e das relações que estabelecem entre si e com as teorias críticas.

\section{PALAVRAS-CHAVE}

teorias de currículo; teoria crítica; campo do currículo.

* Uma versão inicial e reduzida deste texto foi publicada anteriormente, sob encomenda dos editores. Oliveira, I. B.; Süssekind, M. L. From the Critical Theories to the Critique of the Theories: dialogues between social thought and its appropriations through educational debates in Brazil. In: Darder, A.; Mayo, P.; Paraskeva, J. M. (Orgs.). International Critical Pedagogy Reader. London: Routledge, 2015. 


\title{
FROM CRITICAL THEORIES TO THEORIES' CRITICISM: EVIDENCE-BASED STUDY ABOUT THE FRAMING OF DEBATES ON CURRICULA IN BRAZIL
}

\begin{abstract}
The development of curriculum studies in Brazil is marked by the influence of critical theories which remain substantial and perhaps hegemonic even when no longer majoritarian, causing authors of other lines and trends to dialogue with it compulsorily, even if subliminally. Our hypothesis to understand such phenomenon is related to the intrinsic importance of debate when constituting curricula across the country, considering that current post-critical tendencies are linked to a progressive, leftist thinking, to a social, emancipatory and democratic project; it means that to a certain extent, they emerged as the new "leftists", from critical theories and the traditional left. In this way, we aimed to outline the trajectory of such theories and the dialogues promoted by and established between them as a means to understand the current trends in curriculum studies and their relation to critical theories.
\end{abstract}

\section{KEYWORDS}

curriculum theories; critical theory; curriculum field.

\section{DESDE TEORÍAS CRÍTICAS A LA CRÍTICA DE LAS TEORÍAS: UN ESTUDIO INDICIARIO SOBRE LA CONFORMACIÓN DEL CAMPO DEL CURRÍCULO EN BRASIL}

\section{RESUMEN}

En la investigación de la trayectoria del campo del Currículo en Brasil entendemos que incluso cuando la perspectiva de la teoría crítica ya no es mayoritaria, su influencia sigue siendo inmensa y tal vez incluso hegemónico, que obliga a los autores asociados con las otras tendencias y matices de tener un diálogo con él, aunque de una manera subliminal. Nuestra hipótesis se refiere a la importancia intrínseca del debate crítico en la conformación del campo en Brasil, teniendo en cuenta que las actuales teorías proscriticas son en su mayoría vinculadas al pensamiento emancipador y democrático, que, en cierto sentido, surgió como la nueva izquierda desde las teorías críticas y las izquierdas tradicionales. Por lo tanto, tratamos de desinar una historia indiciaria de estas teorías y los diálogos promovidos entre ellos como un elemento para la comprensión de las tendencias actuales en el campo de Currículo y las relaciones que se establecen entre ellos y con las teorías críticas.

PALABRAS CLAVE

teorías curriculares; la teoría crítica; campo del currículo. 


\section{INTRODUÇÃO: PRIMEIRAS PISTAS DAS TEORIAS CRÍTICAS NA EDUCAÇÃO BRASILEIRA}

Atendendo a uma proposta de discussão a respeito das teorias críticas e sua influência no cenário político-epistemológico dos debates no campo de estudos do Currículo no Brasil, formulada por colegas atuando em universidades estadunidenses, buscamos investigar sinais (Ginzburg, 1989) de diálogos entre obras e autores que se destacaram nos últimos quarenta anos no cenário educacional brasileiro, traçando um panorama não exaustivo, porém indicativo, do que vem sendo proposto, criticado e discutido pelos educadores nesse período. Nos textos, nas críticas que estes receberam, nos debates presentes nas entrelinhas das apresentações de cada obra e coleção, recolhemos indícios e sinais sobre os diferentes modos de entender, criar e usar (Certeau, 1994) as teorias críticas e as críticas a estas, historicamente orientados, trazendo ao leitor uma abordagem possível da questão em pauta, com base em pesquisa bibliográfica indiciária (Ginzburg, 1989).

Entendemos, inicialmente, que o desenvolvimento das teorias sociais críticas nos anos da Guerra Fria na Europa e na América do Norte leva à produção de um pensamento crítico em educação que chega e se notabiliza no Brasil a partir dos anos 1960 e 1970, quando intelectuais progressistas e educadores - preocupados de modos diferentes com o social, embora convergentes na direção da justiça social, que aqui identificamos com um pensamento alinhado à esquerda (Bobbio, 1995) opõem-se à ditadura militar recorrendo ao pensamento marxista e aos usos deste para a compreensão do fenômeno socioeducativo. Especialmente a partir das obras A Reprodução, de Pierre Bourdieu e Jean Claude Passeron (1971), A Escola Capitalista na França, de Baudelot e Establet (1971), e A Escola na América Capitalista, de Bowles e Gintis (1981), as relações entre o capitalismo e as políticas educacionais voltadas à perpetuação do status quo no Brasil foram debatidas e analisadas por educadores progressistas, ligados ao universo do marxismo. Com influência menos destacada, mas também relevante, a teoria crítica dos autores ligados à Escola de Frankfurt também se fez presente na mesma época, e depois, com destaque para o pensamento de Jürgen Habermas.

Examinando a obra dos tantos autores brasileiros da época, encontramos grande diversidade de enfoques e ênfases, nem todos diretamente relacionados às políticas educacionais ou aos currículos, todos relevantes para o estudo dessa importante influência exercida pelos debates críticos no pensamento educacional brasileiro, em uma espécie de debate nem sempre explícito com teorias educacionais mais tradicionais. Ainda nos anos 1970, muitas obras inspiradas nas teorias críticas e refletindo sobre questões da educação brasileira foram publicadas, apesar da parca produção editorial no campo da educação na época - de certo modo compatível com a produção acadêmica, ainda incipiente na área - e da ditadura militar, que tornava arriscado criticar o capitalismo e suas instituições a partir de um ponto de vista marxista. Ainda assim, autores como Luiz Antônio Cunha, Carlos Roberto Jamil Cury, Vanilda Paiva, Maurício Tragtenberg e Wagner Rossi, entre outros, produziram obras que se tornaram ícones para as gerações seguintes de educadores críticos. Cabe ressaltar que não só as reflexões de europeus e norte-americanos ins- 
piraram esses debates, mas também a obra de Paulo Freire — nos anos 1970 mais publicada fora do que dentro do Brasil - exerceu influência sobre esses autores.

Aqui, um parêntese se impõe. Paulo Freire, e suas ações educativas no final dos anos 1950 e nos anos 1960, talvez tenha sido, com grande autonomia intelectual e destacando-se pelo compromisso político concreto com as camadas pobres da população, o primeiro grande autor brasileiro que pode ser relacionado às teorias educacionais críticas, antes mesmo que seus pares europeus e estadunidenses produzissem suas obras e fizessem sucesso por aqui, o que o tornaria um autor crítico avant la lettre. Suas obras Pedagogia do Oprimido (Freire,1970) e Educação como prática de liberdade, ambas escritas nos anos 1960, são ainda hoje obras icônicas no campo do pensamento educacional progressista, ligado ao pensamento político de esquerda, defendendo as bandeiras do socialismo e da igualdade social. Elas foram produzidas com base em experiências efetivas desenvolvidas pelo autor em recantos pobres e analfabetos do Brasil, comprometidas com a emancipação dessas populações por meio da apropriação de conhecimentos formais, sempre respeitando aquilo que os trabalhadores com quem atuava já conheciam. Freire buscava - e morreu, em 1997, buscando -, por diferentes caminhos, superar a alienação do povo, propondo uma educação voltada à conscientização, pensando a descolonização do terceiro mundo pela educação, agindo em clara crítica ao modelo da escola capitalista burguesa que mantinha e realimentava a opressão das massas, como afirma no Esclarecimento constante na obra Educação como prática de liberdade (Freire, 1982, p. 35-36). Freire influenciou e continua influenciando enormemente pensadores críticos, mesmo outros que lhe sucederam, espalhados pelo mundo, notadamente Henry Giroux e Michael Apple.

Uma das mais importantes questões no campo da educação no Brasil, ao menos nos últimos cinquenta anos, tem sido a discussão sobre as relações entre política e educação. $\mathrm{O}$ exemplo e a influência de Paulo Freire, tanto como pensador quanto como secretário de Educação, nos idos de 1960 e 1982, são igualmente notáveis. A alfabetização de trabalhadores no Nordeste no fim dos anos 1950 e início dos anos 1960 foi apenas uma de um amplo número de experiências emancipatórias nas políticas educacionais daquela época que a ditadura (1964-1985) tentou apagar instituindo sua própria reforma educacional. Pode-se dizer que uma conversa complicada (Pinar, 2012) sobre experiência já se desenhava nos círculos de debates sobre as teorias em educação, embora sempre tenha parecido muito mais importante para a maior parte dos pesquisadores brasileiros no campo da educação, sobretudo aqueles sob influência da intelligentsia gramsciana e marxista, manter o foco nos temas da economia e do poder (Pinar, 2011; Süssekind e Pinar, 2014).

Essa reflexão nos leva a considerar a hipótese de que, apesar das dificuldades já citadas, os autores que emergem nos anos 1970 e suas obras críticas também foram influenciados pelo pensamento e pelas experiências freireanas, proibidos e coibidos pela ditadura militar, mas presentes na mente daqueles que com elas conviveram e puderam relacioná-las às reflexões que chegavam de além-mar. Assim, podemos compreender a discussão proposta por Luiz Antônio Cunha, que já em 1972 entendia ser preciso pensar de modo menos ingênuo as políticas educacionais (Cunha, 1977a, p. 9). A partir de 1973, Cunha desenvolve um trabalho de reflexão educacional centrado em análises sociológicas do pensamento liberal e de sua 
influência no pensamento educacional brasileiro e na estrutura escolar, mostrando sua relação com a desigualdade de oportunidades educacionais entre crianças das classes populares e da burguesia (Cunha, 1977b). Essa é uma pista marcante no caminho investigativo que traçamos.

Trabalhando sobre a obra de liberais famosos - dos campos da economia, sociologia e mesmo filosofia - para o seu pensamento, Cunha (1977a; 1977b) usa inúmeras referências a economistas de esquerda ${ }^{1}$ e dados quantitativos ilustrando sua argumentação, que já se utiliza das obras de Bourdieu e Passeron, Baudelot e Establet e Bowles e Gintis em sua crítica ao sistema educacional brasileiro e à reprodução social que enseja. Não por acaso, no livro em questão aparecem como obras da mesma série, Educação em Questão, a obra de Pierre Bourdieu e Jean Claude Passeron, $A$ Reprodução ${ }^{2}$, ao lado de outras ligadas a pedagogias não diretivas e a debates educacionais que extrapolavam o tecnicismo hegemônico na época e o pensamento liberal capitalista que lhe servia de base. $\mathrm{O}$ trabalho do autor evidencia a penetração quase imediata da produção crítica em educação no Brasil e foi amplamente divulgado e utilizado nas universidades durante aquele período. Hoje, Cunha é reconhecido como um dos precursores da reflexão educacional de esquerda no país. Embora, segundo João Paraskeva (2011), ao ir fundo nos debates entre os autores citados seja mais fácil evidenciar conflitos e nuances do que categorizar quem são efetivamente os críticos, os democratas e os progressistas, afirmamos que, no caso do Brasil, essas definições parecem mais claras.

Considerando o papel icônico de Paulo Freire e também a importância do contexto sociopolítico da época, podemos afirmar que, no campo do Currículo, e mesmo no das teorias educacionais em geral, o acirramento político fomentou uma dicotomia clara entre críticos (marxistas e adeptos de Bourdieu) e capitalistas, secundarizando, pelo menos na década de 1970, o embate entre críticos e progressistas de outros matizes. Essa dicotomia separou claramente o uso dos termos progresso e eficiência, de um lado, e democracia, autonomia e compromisso político, de outro, como explicita o clássico de Guiomar Namo de Mello, Magistério de $1^{\circ}$ grau: da competência técnica ao compromisso político (1a edição em 1982), e reforça o ainda mais importante, estudado e discutido Educação: do senso comum à consciência filosófica (1a edição em 1981), de Dermeval Saviani. É importante notar que ambas as visões valorizam o papel da escola e dos conhecimentos escolares, ainda que com metas distintas.

Voltando à década de 1970, outros autores e obras do período foram importantes na formação das gerações subsequentes e das críticas aos críticos que advieram dos debates educacionais dessa época, sobretudo a partir da emergência das novas esquerdas, mais comprometidas com a justiça social globalmente concebida do que com a transfor-

1 Conforme afirmado acima, entendemos como pensamento de esquerda, em suas diferentes tendências e matizes, aquele relacionado à crítica do capitalismo e das exclusões promovidas por esse sistema e que se propõe a lutar pelo socialismo e pela construção de uma sociedade mais justa e igualitária.

2 Originalmente chamado de A Reprodução: elementos para uma teoria do sistema escolar. 
mação do sistema econômico ${ }^{3}$ no período de redemocratização do país, notadamente a partir da segunda metade dos anos 1980. É nesse período que o pensamento de Jürgen Habermas chega ao campo da educação no Brasil. A publicação de $A$ Reconstrução do materialismo histórico, em 1981, e o lançamento de uma coletânea de seus textos junto a outros autores da Escola de Frankfurt, em 1983, representam um marco na penetração de outros enfoques críticos no pensamento educacional do país. A defesa que o autor faz de que, para além das condicionantes estruturais, a realidade social conta com um mundo da vida que torna impossível fazer inferências imediatistas do que cada realidade é a partir da estrutura na qual se inscreve contribui para a luta contra um estruturalismo que anula as especificidades dos diferentes espaçostempos ${ }^{4}$ sociais. Assim, mantém-se na tradição crítica frankfurtiana, sem aderir à automatização das relações entre as estruturas sociais e a realidade social que em cada espaçotempo elas tornam possível. Outros pensadores seguiram a esteira do pensamento educacional crítico e dos debates suscitados por Habermas, crescentemente incrementados pelas reflexões pós-críticas (Silva, 1999), muitas delas situáveis no campo do pós-estruturalismo e suas múltiplas tendências, mais ou menos próximas do pós-modernismo ${ }^{5}$.

Nessa direção, Paraskeva (2011, p. 20), em estudo sobre o campo do Currículo, argumenta que o compromisso dos teóricos críticos e progressistas com a justiça social e a igualdade foi incorporado a esse debate, trazendo ao protagonismo conceitos como ideologia, hegemonia, senso comum, currículo oculto, poder, reprodução, resistência, transformação social, emancipação, classe, gênero e raça, entre outros, que redefiniram o campo internacionalmente nos anos 1980 e 1990. Ele aposta que, hoje, para alguns dos teóricos críticos progressistas, a justiça cognitiva acompanha como condição sine qua non a justiça social e a democracia real como questões primordiais (Paraskeva, 2011, p. 21).

Nessa sucessão de obras e discussões, ainda no fim dos anos 1970, cabe destacar o livro Ideologia e educação brasileira: católicos e liberais (Cury, 1978), cuja apresentação, escrita por Alceu Amoroso Lima ${ }^{6}$, pensador católico e progressista

3 Essas tendências políticas surgem a partir dos movimentos libertários de 1968 e da crítica ao regime soviético, em que houve privação de liberdades individuais e perseguições políticas a amplos grupos sociais cujas ideias divergiam daquelas do regime. A nova esquerda se configura, portanto, na esteira da crítica ao marxismo ortodoxo e ao economicismo, trazendo para a luta política pautas como a do feminismo, da ecologia, do livre exercício das sexualidades e de outras minorias, diferenciando-se, com isso, da esquerda marxista e da primazia do econômico por ela defendida, conforme interpretamos nas pistas e sinais que caçamos nas fontes pesquisadas e considerando o debate de Bobbio (1995).

4 A junção de termos, opostos ou complementares, em uma única palavra visa a superar a cisão indicada entre ambos, substituindo-a pela ideia de que são indissociáveis.

5 A complexidade deste debate e a multiplicidade de autores e tendências que nele se situam exigiriam, por si só, outro texto, cabendo aqui a menção à oposição entre autores identificados com um ou outro campo do pensamento contemporâneo.

6 Lado a lado ao suporte político da Igreja às oligarquias e conservadorismos, frutifica tanto um pensamento marxista dentro de setores das igrejas católica e protestante (Teologias da Libertação e Pastoral da Terra) quanto um pensamento social marxista e de inspiração teleológica que chega a influenciar significativamente a obra e o entendimento da obra de Paulo Freire (Kumar, 2011; Pinar, 2011). 
que batia-se contra os desmandos da ditadura militar, traz o inequívoco vínculo da obra com o pensamento crítico. Referindo-se ao modo como Cury acusa ambos os grupos que estuda - católicos e liberais - de defenderem os interesses das classes dominantes, Lima assume um terceiro ponto de vista.

Nem o ponto de vista espiritualista assumido pelos católicos, nem o pragmatista assumido pelos pioneiros. Sua posição é marxiologista, segundo a qual o fato essencial da sociedade humana, até hoje, é estar dividida em dois planos antagônicos: o dos opressores e o dos oprimidos. (Cury, 1978, p. X)

Na orelha desse livro, o professor Casemiro dos Reis Filho destaca que a dissertação de mestrado que the deu origem se inscreve no impulso do desenvolvimento da pós-graduação no Brasil. Aqui, mais uma importante variável para a compreensão da chegada e da proliferação do pensamento crítico em educação no Brasil: o grande investimento na ampliação e consolidação da pós-graduação feito no período ditatorial. Isso contribuiu para a formação de pensadores e intelectuais nas mais diversas áreas do conhecimento, em programas de formação que incentivaram a pós-graduação no país, estabelecendo, também, diálogos relevantes com intelectuais de países da Europa e dos Estados Unidos. Muitos desses precursores do pensamento crítico em educação no Brasil tiveram contato com obras de referência ao estudarem, nos países em que elas surgiram, com colegas dos seus principais autores ou mesmo com os próprios.

Ainda nos anos 1970, em crítica ao pensamento educacional que acusa de ideológico, Vanilda Paiva publica, em 1977, dois artigos nos quais retoma o pensamento freireano e o de Pierre Furter - que andara no Brasil nos anos 1960 e fora parceiro de Freire, tendo inclusive assinado a orelha do livro de Freire aqui já citado - para criticar autores que se referiam à educação permanente e a propostas de políticas educacionais atreladas a esse pensamento, algumas advindas da Organização das Nações Unidas para a Educação, a Ciência e a Cultura (Unesco), de modo idealista e deslocado do debate fundamental em torno das questões econômicas e de formação do trabalhador. Republicados em livro em 1985 (Paiva e Rattner, 1985), os textos de Paiva foram complementados com um de Henrique Rattner, todos comprometidos com a perspectiva crítica da educação, em oposição aos tecnocratas e aos grupos considerados ingênuos (não críticos), cuja fé na capacidade transformadora da educação negligenciaria os fatores políticos e econômicos aos quais estaria irremediavelmente atrelada e dos quais seria dependente. Ressalte-se aqui a discussão de Rattner a respeito da crítica à teoria do capital humano, muito presente em obras da primeira metade dos anos 1980 no Brasil, com destaque para A Produtividade da escola improdutiva, de Gaudêncio Frigotto (1994), publicado pela primeira vez em 1984 e que analisa, segundo consta em sua orelha, "a raiz do pensamento economicista burguês que influenciou a educação nas últimas décadas". De modo igualmente crítico em relação ao pensamento burguês e à tecnocracia que lhe subjaz no planejamento educacional brasileiro durante a ditadura militar, Baía Horta (1983) assume, também, a teoria crítica como meio de superação da ingenuidade política e sociológica do pensamento e das propostas tecnocráticas.

Na mesma linha, outra de muitas obras emblemáticas do período é Capitalismo e Educação, de Wagner Rossi, publicado em 1980. O título evidencia o perten- 
cimento de Rossi ao grupo dos teóricos críticos em educação que se notabilizaram no período. A esclarecedora orelha do livro, que inclui o subtítulo, ausente na capa, Contribuição ao estudo crítico da economia da educação capitalista - não assinada e, por isso, provavelmente escrita pelo autor - , serve como resumo do ideário crítico da época. Essa obra insere-se entre os trabalhos de crítica à educação institucional que, apenas na segunda metade dos anos 1970, compuseram um novo quadro para as discussões sobre a realidade educacional brasileira. De certo modo, o livro complementa e desenvolve, especialmente em suas implicações econômicas, o campo de estudos em que foram pioneiros os trabalhos de Luiz Antônio Cunha, Manfredo Berger, Barbara Freitag e Mirian Jorge Warde, entre outros.

Assumindo-se como obra que parte da crítica ao pedagogismo "dos que pretendem resolver os problemas sociais através da escola”, Rossi (1980) anuncia ir além da mera constatação de que a educação reproduz a sociedade vigente, desvelando, para além dessa função,

as contradições que invadem a escola, assim como as demais instituições sociais sob o capitalismo, e que derivam, radicalmente, das contradições inerentes à estrutura de produção da sociedade que opõe detentores dos meios de produção e da força de trabalho. De um lado verifica-se o papel desempenhado pela educação capitalista enquanto inculcadora da ideologia hegemônica e sociabilizadora dos dominados e enquanto instrumento de ampliação da capacidade de produção da força de trabalho, com o que se desmistifica o caráter ilusório da democratização da educação e demais propostas liberais, ao mesmo tempo em que se oferece uma contrafacção demolidora a toda a concepção tradicional da economia da educação, e à sua criação teórica do capital humano. (Rossi, 1980, p. 8)

Nesse conjunto de obras, a questão curricular aparece de modo secundarizado em relação aos debates econômicos e político-ideológicos, em parte porque o entendimento majoritário era de que a estrutura reprodutivista era inevitável e incontornável pedagogicamente, em parte porque não havia, nessa linha de pensamento, espaço para as especificidades dos conhecimentos em jogo nas práticas educacionais, consideradas superestruturais, ou seja, dependentes e derivadas da infraestrutura econômica que definia o perfil da escola e, portanto, das propostas e práticas curriculares. Podemos considerar o clássico Uma escola para o povo, de Maria Teresa Nidelcoff (primeira edição brasileira em 1978) uma exceção a essa regra, pois a autora discute questões especificamente escolares, como os objetivos e conteúdos do fazer escolar. Em 1981, destaca-se outro clássico dedicado ao estudo e à reflexão sobre o que se passa dentro das escolas, refletindo sobre o fazer docente: o já citado Magistério de $1^{\circ}$ grau: da competência técnica ao compromisso político, de Guiomar Namo de Mello.

\section{O CAMPO DO CURRÍCULO ASSUME O DEBATE: ANOS 1980 EM DIANTE}

No entanto, mesmo nessa época já havia muito mais discussões específicas em torno das questões curriculares, as quais começaram a ganhar corpo no Brasil no início dos anos 1980. A publicação da obra Currículo e Ideologia, de Michael Apple (1982), 
no início do período, é exemplar em relação a isso. Apesar da pouca divulgação no Brasil, um exame mais detalhado dessa produção estadunidense e europeia mostra que, na esteira das obras emblemáticas já citadas sobre as relações entre o capitalismo e a educação, abriu-se um imenso campo de discussão especificamente curricular já nos anos 1970, que, embora tardiamente, chegou com força ao Brasil a partir de meados dos anos 1980, notadamente pelas mãos de Antônio Flávio Moreira e Tomaz Tadeu da Silva. Durante mais de dez anos, esses autores destacaram-se com uma produção no campo curricular que nos atualizava em relação ao que se vinha produzindo no exterior, ao mesmo tempo em que buscavam dialogar com as especificidades da nossa educação. Papel importante nessa divulgação foi desempenhado pela ampliação da produção editorial na área de educação que, dos anos 1970, quando se produzia pouco, aos anos 1990, cresceu e se desenvolveu imensamente, respondendo tanto ao próprio desenvolvimento da produção nacional quanto à abertura para a publicação de obras censuradas no período da ditadura e ao reconhecimento do valor acadêmico da produção no campo da educação no Brasil e no exterior.

Podemos considerar que, a partir da produção incipiente da década de 1970 e da abertura política iniciada no final da década, os anos 1980 foram marcados por uma ruidosa e ampla divulgação do ideário crítico e de seus autores. Dermeval Saviani, Gaudêncio Frigotto e Moacir Gadotti são apenas alguns dos que se destacaram no período. Embora ainda predominante, a perspectiva crítica em educação já não destaca apenas as análises econômicas e economicistas na década de 1980.

Moacir Gadotti, assumidamente freireano e marxista, em suas obras mais conhecidas ${ }^{7}$ destaca sempre a influência sobre si do pensamento gramsciano, bem como questões relacionadas à luta de classes, mas, logo na apresentação de Educação e Compromisso (1985), assume também a discussão em torno das questões próprias à escola, para além das determinações econômicas e mesmo políticas e sociais. Gadotti recupera do pensamento escolanovista ${ }^{8}$ (liberal em sua maioria) a importância de a escola e os educadores assumirem papel ativo na luta pela transformação da sociedade. $\mathrm{O}$ autor assume a importância de os educadores "cansados de ouvirem uma crítica inconsequente à escola" (Gadotti, 1985, p. 12) buscarem "projetos menos ambiciosos, mas que lhes tragam alguma satisfação ao nível mais imediato". Ele afirma, ainda, que "outros procuram trabalhar os fatores intraescolares, que explicam a deterioração do ensino". $\mathrm{Na}$ continuidade dessa apresentação, aponta como problema a dificuldade de "superar a dicotomia entre saber e poder, entre competência técnica e compromisso político, a dificuldade de integrar a competência técnica no compromisso político" (Gadotti, 1985, p. 13), evidenciando sua busca pela superação da dicotomia instalada no país entre teóricos críticos e conservadores nä̈ves ou ingênuos (Gadotti, 1985, p. 13).

Muitos outros autores, brasileiros e estrangeiros, surgem com perspectivas críticas que transcendem as ideias da escola como mera reprodutora das relações

7 Além da aqui citada, ressaltamos: Educação e poder: introdução à pedagogia do conflito, de 1980, e Concepção dialética da educação: um estudo introdutório, de 1983.

8 Nos anos 1930 temos, em Anísio Teixeira e seu diálogo direto com John Dewey, a referência maior. 
infraestruturais. A nova sociologia da educação, surgida na Inglaterra, e todo o pensamento crítico ampliado estadunidense, e mesmo europeu continental, ganham nuances e variações que, podemos nos arriscar a dizer, desembocam na emergência do pensamento pós-crítico, relacionado ao desenvolvimento das perspectivas pós-estruturalistas e também à viragem cultural tão bem analisada por Hall (1998) e outros. Importante destacar que é no final da década de 1980 que o livro de Justa Ezpeleta e Elsie Rockwell (1986), Pesquisa Participante, é publicado no Brasil. Tornando-se emblemática e de alta relevância para a reflexão educacional em geral e curricular em particular, a obra pode ser considerada a pedra fundamental dos estudos do cotidiano escolar no Brasil, hoje uma importante e inovadora perspectiva no campo de estudos do Currículo, dentro e fora do país (Pinar, 2011).

Ou seja, também a partir do início dos anos 1980, com a abertura democrática e a posterior redemocratização do país, ideias defendidas por grupos políticos ligados aos movimentos sociais e culturais silenciados no período da ditadura, com destaque para o pensamento freireano, reemergem e passam a compartilhar com os estudos críticos o espaço das discussões educacionais em geral e curriculares em específico. A visibilização de um ideário político e social, crítico também do economicismo e do estruturalismo, hegemônicos até então, cria e dá consistência a estudos e interpretações da questão educativa no Brasil em debate com a teoria crítica anterior. O campo do Currículo se consolida, a partir dessa ampliação do espaço de debates, como campo específico de debates em educação não necessariamente vinculado apenas à seleção e organização dos conhecimentos e sua distribuição pelas disciplinas e séries de escolarização ou aos modos de transmiti-los ou mesmo de avaliar sua aquisição. A politização dos debates sociais e educacionais dá a tônica daquilo que, a partir desse período, constituirá o campo no Brasil: as perspectivas sob o questionamento a respeito de quais bases suportam as estruturas do poder e produzem a manutenção das desigualdades sociais. Autores com Michael Apple, Michael Young, William Pinar, Henry Giroux e Peter McLaren emergem como referências importantes nesse cenário, mesmo que inicialmente pelas mãos de educadores e intelectuais brasileiros. São autores que se associam às teorias críticas, mas que superam amplamente as perspectivas reprodutivistas dos anos 1970.

Podemos afirmar que a noção de currículo oculto, que evidenciava pedagogicamente a presença nas salas de aula de questões levantadas pelos teóricos críticos, e o movimento de reconceitualização curricular foram de suma importância para a própria constituição do campo dos estudos curriculares no Brasil a partir da década de 1980, na medida em que contribuíram para que pudesse escapar dos debates meramente formalistas das perspectivas tradicionais ou dos metodologismos ligados ao escolanovismo e outras perspectivas pedagógicas não diretivas, ou ainda aquelas fundamentadas em análises e propostas advindas da psicologia, como as escolas piagetianas, em voga no final dos anos 1970 e início dos anos 1980.

Apesar de minoritários, intelectuais e educadores críticos da própria teoria crítica também se fazem presentes nos debates e propostas educativas do período pós-ditatorial. Usando elementos de reflexões produzidas pelos estudos culturais, pelos historiadores, pelos movimentos sociais de minorias diversas, pela antropologia das sociedades complexas e outras vertentes da reflexão social e política contem- 
porânea, eles inscrevem-se no cenário educacional em uma perspectiva pós-crítica, como desenvolve Tomaz Tadeu da Silva, em obra de 1999, na esteira de trabalhos anteriores desenvolvidos em parceria com diferentes autores (Silva, 1999).

No início dos anos 1990, uma coleção intitulada Ciências sociais da educação trouxe reflexões críticas de matizes múltiplos para o debate educacional e curricular brasileiro, mostrando a força de sua influência no pensamento educacional e curricular. No texto de apresentação de um dos livros da coleção, Teoria crítica e educação, publicado em 1994, Silva resume:

É possível afirmar que a teorização crítica em educação alcançou hoje um estágio respeitável de maturidade e elaboração. Para isso contribuiu toda uma geração de educadores/as, teóricos sociais, historiadores e filósofos da educação que, gradualmente, foram construindo o que hoje já pode ser considerado como uma tradição de pensamento educacional e pedagógico. Paulo Freire, Michael Young, Pierre Bourdieu, Basil Bernstein, Samuel Bowles e Herbert Gintis, Louis Althusser - apenas para citar alguns dentre os pioneiros -, Michael Apple, Henry Giroux, Peter McLaren, Thomas Popkewitz, Jennifer Gore - de novo, apenas para citar algumas das pessoas dentre as mais ativas atualmente - abriram o pensamento e a análise educacional a novas formas de pensar, a novas formas de análise, a novas e reveladoras metáforas. Educação bancária, currículo oculto, reprodução cultural, código, capital cultural, aparelhos ideológicos de estado são expressões que fazem hoje parte do vocabulário corrente e obrigatório da análise educacional crítica. A própria noção de crítica é parte integrante e fundamental dessa tradição. (Pucci, 1994, p. 7)

No mesmo período, mais especificamente no campo do Currículo, junto a Antônio Flávio Moreira, Silva publica duas obras que se tornariam emblemáticas: Currículo, cultura e sociedade, em 1994, e Territórios contestados, em 1995. Ambos os livros declaram a superioridade da teoria crítica, o que, em certo sentido, desenharia o campo e seus debates durante os anos 1990. Moreira publica no mesmo período, em 1990, Currículos e programas no Brasil, obra de referência em que discute a constituição do campo no país sob a perspectiva do crescimento dos programas de pós-graduação e as influências que recebe desde os primórdios de sua constituição, chamando atenção para a necessidade que sentiu de incorporar a literatura crítica a seus cursos de Currículos e programas depois de ler Ideologia e Currículo, de Michael Apple, e Knowledge and control, editado por Michael Young. Nos mesmos anos 1990, Tomaz Tadeu da Silva continuou a produzir obras coletivas com a participação de pensadores de diversos países e ambos os autores assumem posição acadêmica relevante na interlocução dos estudos do campo no Brasil com a produção educacional crítica europeia e estadunidense, ampliando os debates curriculares e contribuindo para o desenvolvimento do campo no Brasil.

A obra Documentos de identidade: uma introdução às teorias do currículo, de Silva, publicada em 1999, é, desde a sua publicação, uma das principais referências, junto aos outros livros emblemáticos publicados com Moreira (1994 e 1995), para a iniciação aos estudos no campo, propondo a classificação do pensamento curricular 
em três grandes grupos: teorias tradicionais, teorias críticas e teorias pós-críticas. Praticamente uma bíblia para os estudantes da formação de professores, a teoria crítica é apresentada neste livro como a melhor maneira — ou, ainda, a única maneira — de entender o currículo diante dos desafios de seu tempo.

Além disso, a classificação de Silva tornou-se um paradigma dos estudos curriculares no Brasil. Naquele tempo, seus principais autores eram um grupo de pesquisadores que entendiam currículo como um diálogo com a cultura, o poder e a política. Silva, deliberadamente, justifica o silenciamento das outras teorias, que para ele forneciam explicações sobre a relação currículo e sociedade que não eram tão importantes, como a autobiografia. Reeditado mais de dez vezes, o livro de Silva define que teorias são visões de mundo e, por isso, algumas são melhores do que outras (Silva, 1999, p. 3). Em sua visão da reconceitualização, nos Estados Unidos, elucida que a consequência do confronto com o pensamento curricular tradicional é o antagonismo entre aqueles que se preocupam em criticar o status quo da escola e do currículo sob a ênfase do papel da economia e das relações de poder e os outros. Moreira (2007) utiliza a classificação de Silva para notar a dominância da teoria crítica durante a consolidação do campo ao longo das décadas de 1980 e 1990 . Ao mencionar a influência dos debates da reconceitualização sobre os novos temas que aparecem no campo, ora iluminado pela forte entrada dos enfoques do pós-estruturalismo do início dos anos 2000, ele, estudioso da nova sociologia, ressalta especialmente a contínua influência de Michael Apple e Henry Giroux.

Para Torres (1998), Paulo Freire é a principal inspiração crítica e uma das maiores referências do campo brasileiro. Para esse autor, também, os estudos críticos oferecem "as ferramentas necessárias para entender totalmente e combater a relação entre educação e poder cultural, política e econômico desigual” (Torres, 1998, p. 15). Foi esse entendimento de educação e sociedade que não só formatou os debates em currículo por muitos anos como também relegou quaisquer outras noções de currículo a um lugar menos importante como teoria de entendimento da sociedade.

Em um artigo de 2002, Moreira analisa o movimento de reconceitualização e sublinha, nas tendências teóricas pós-críticas, as rejeições comuns. Para ele, são elas: o currículo como uma prescrição; o caráter apolítico dos estudos no campo antes da reconceitualização; a falta de historicidade; a excessiva preocupação com a melhora dos resultados escolares; e a indefinição do objeto do campo de estudo. Todas essas rejeições e a polarização posterior de estudos de currículo entre política e poder e experiência (Süssekind e Pinar, 2014) também são características proeminentes do campo no Brasil naquela época, embora estudiosos brasileiros costumem beber mais na fonte dos europeus do que dos norte-americanos. Além de enormes influências da Escola de Frankfurt e da sociologia da vida cotidiana francesa, outras teorias inspiraram diversos autores e ganharam espaço na cena de debates desde aquela época. Tanto a tendência reconceitualista neomarxista, representada no Brasil pela forte influência de Michael Apple e Henry Giroux, quanto a nova sociologia da educação, representada por Michael Young, serão bem divulgadas e seguidas. O diálogo tardio com tendências mais humanistas e autobiográficas, bem como com outras tendências não marxistas da reconceitualização, abre amplo espaço para questionamentos pós-estruturalistas (Süssekind e Pinar, 2014) e para novos 
autores como Ivor Goodson (1995) e seu foco na historicidade das disciplinas dos currículos e nas narrativas de identidades.

Moreira (2001), mapeando os debates do campo nesse período, abre a discussão sobre o multiculturalismo ao investigar as noções de currículo presentes em 46 artigos apresentados na reunião anual nacional de pesquisadores promovida pela ANPEd ${ }^{9}$. Ele verifica que os estudos abordam o debate discutindo currículo e relações raciais; currículo e diversidade cultural; currículo, multiculturalismo e políticas de currículo; multiculturalismo e formação de professores; e currículo e gênero. Apenas um artigo assumiu o tópico de currículo e classe social. Com base em sua análise dos temas tratados na maioria das vezes nesse grupo de artigos, Moreira identifica apenas um autor como grande influência no campo (Moreira, 2001, p. 73), Peter McLaren, embora reconheça a presença de outros autores, incluindo uma definidora influência espanhola, nessa década, nomeadamente a partir dos debates que trazem Gimeno Sacristán e Jurjo Torres Santomé, autor de El curriculum oculto (1994). Moreira expressa inquietude com o papel secundário que o conceito de classe social adquiriu como sujeito dos estudos curriculares (Moreira, 2001, p. 72).Para ele, a raison d'être do campo seria de que o conceito de classe social não pode, absolutamente, ser esquecido quando se trata de debater currículo em um país com tantas desigualdades sociais (Moreira, 2002, p. 93). Mais, tarde, Moreira, colaborando em outro livro, publicado com Regina Leite Garcia (2003), Currículo na contemporaneidade: incertezas e desafios, traz autores que, a partir de abordagens diversas, discutem questões do campo do currículo sem necessariamente trazer questões relacionadas a estudos de classes. O interesse na publicização da produção internacional e da circulação da diversidade do campo assume prioridade em relação a esta ou aquela tendência específica.

Desde 1988, vivendo sob um movimento de democratização da sociedade, observamos no Brasil a ampliação das ações afirmativas, ao mesmo tempo em que se consolida o estado republicano com base no federalismo e na representatividade, assolado por fisiologismo e corrupção. Enquanto isso, apesar de inegáveis avanços econômicos, o país ainda se debate com imensas desigualdades sociais e a frequente depreciação da miscigenação e da diversidade cultural. Por essa razão, poder, economia, política, cultura, identidade, colonização e democracia têm sido importantes temas para os pesquisadores em educação que se dedicam ao campo do Currículo. Não obstante, nesse contexto, é compreensível que as ideias marxistas tenham sido inspiradoras não só de críticas sociais e educacionais, mas que os teóricos críticos tenham dominado o campo por tanto tempo. Sob esse enfoque, os teóricos críticos escreveram a história do campo, embora isso não o dispa de pluralidade ou complexidade, sendo, para Pinar, tão teoricamente sofisticado que apenas saber dele abre possibilidades para

a provocação de uma miríade de trocas, a maioria das quais não irão ocorrer em inglês ou ser publicados na América do Norte, mas serão reconhecidos nas histórias disciplinares que os futuros estudiosos de currículo serão obrigados a escrever. (Pinar, 2011, p. 3-4)

9 Associação Nacional de Pós-graduação e Pesquisa em Educação. 


\section{OS ANOS 2000, OUTRAS PISTAS E NOVAS TENDÊNCIAS: O CAMPO DO CURRÍCULO PARA ALÉM DA CRÍTICA}

Voltando a 2001, Criar currículo no cotidiano pode ser considerado um (pequeno) livro revolucionário na história do campo no Brasil. Conversando com professores e escrevendo sob a forma de conversas entre eles, Nilda Alves, Elizabeth Macedo, Inês Barbosa de Oliveira e Luiz Carlos Manhães desenham uma proposta epistemológica nova e única (Pinar, 2011; Süssekind, 2012), tecendo termos que associam redes a conhecimentos e curriculo a criação. Em diálogo com os teóricos críticos, liberais, ingênuos, mas indo muito além, enfrentam a hegemonia paradigmática, inaugurando algo como a crítica da crítica. Utilizam-se da junção de palavras e discutem não apenas as noções trazidas pelos pós-estruturalistas, mas também, literalmente, usam estratégias de desconstrução epistemológica e metodológica (Pinar, 2011) nas práticas de pesquisa e nas teorizações delas decorrentes. Consequentemente, seria inevitável o enfrentamento com os teóricos críticos e com os defensores do paradigma positivista científico, ambos, de certo modo, dominantes em seus campos, sobre o que são conhecimento, curriculo, invenção ou sobre o protagonismo e potencial emancipatório atribuído às escolas e aos saberes dos professores.

A partir do início dos anos 1990, e da leitura e discussão do livro de Ezpeleta e Rockwell já referido, incomodadas com a hegemonia dos estudos que consideravam a escola como lócus de ignorância e repetição (Bourdieu, 2003) apenas, as professoras Nilda Alves e Regina Leite Garcia (2008), na época atuando na Universidade Federal Fluminense (UFF), e, paralelamente, a professora Corinta Geraldi, na Universidade Estadual de Campinas (Unicamp), assumiram, crescentemente, o cotidiano (Certeau, 1994) como espaçotempo de produção/criação/invenção de conhecimentos - e de currículos - passando a adotá-lo como lócus privilegiado de pesquisa. $\mathrm{O}$ aprofundamento desses estudos, bem como o crescimento das pesquisas realizadas com base neles (Alves e Oliveira, 2008), favoreceu o desenvolvimento do campo e deu origem ao que se faz hoje em diversos grupos espalhados pelo Brasil, dentre os quais se destacam, além dos já citados da UFF e da Unicamp, os grupos da Universidade Federal do Espírito Santo (Ufes) e da Universidade do Estado do Rio de Janeiro (UERJ), dos quais fazem parte inúmeros pesquisadores ${ }^{10}$ e ainda alguns que, sem se definirem como cotidianistas, incorporam e utilizam muito dos conhecimentos que vêm sendo produzidos e divulgados com base nesses referenciais (Süssekind, 2012).

Juntas, Nilda Alves e Inês Barbosa de Oliveira teceram redes de pesquisadores de vulto nacional e internacional e, hoje, há pesquisadores de todos os cantos do país, lendo e pesquisando sob influência dos estudos nosdoscom os cotidianos em educação.

10 Além das já citadas pioneiras (Nilda Alves hoje atua na UERJ), temos notadamente o grupo da UFES, coordenado pelo professor Carlos Eduardo Ferraço, e um grupo sob a coordenação de Inês Barbosa de Oliveira, também na UERJ, além de um grupo na Universidade Federal do Estado do Rio de Janeiro (UNIRIO), sob a coordenação de Maria Luiza Süssekind e Carmen Sanches Sampaio. 
Nessas redes atuam pesquisadores em busca de aprofundar as reflexões em torno da ideia de que o cotidiano é o espaçotempo de criação de ideias e conhecimentos e que o senso comum não é a ausência de reflexão política e epistemológica sobre a realidade (Bourdieu, 2003), seus condicionantes e processos. Entendem esses como espaçotempo de criação e originalidade (Certeau, 1994; Alves e Oliveira, 2008). Daí a necessidade que reconhecem de avançar na compreensão do que é e do que pode representar o cotidiano, enquanto totalidade complexa na qual estão presentes e enredadas as diferentes dimensões da vida social, e os modos como os praticantes da vida cotidiana (Certeau, 1994) nela atuam, sempre de maneira singular e única, em virtude do próprio dinamismo intrínseco ao viver. Nessas redes estão professores e pesquisadores que atuam nos e pesquisam os cotidianos das escolas, reconhecendo neles a produção de conhecimentos e de currículos singulares.

Depois de uma frutífera cooperação com Moreira nos anos 2000, notadamente com a obra Currículo, práticas pedagógicas e identidades, e com os cotidianistas (Alves et al., 2001), Macedo desenvolve sua própria teoria sobre currículo, políticas e práticas, cunhando a teoria do curriculo como enunciação (Pinar, 2011, p. 16). Como uma das figuras de maior liderança no campo brasileiro na atualidade, ela conjuga do questionamento sobre a separação usual entre currículo formal e currículo em ação (Lopes e Macedo, 2011, p. 2). Sua obra e a de seus seguidores vêm contribuindo decisivamente para o aprofundamento e a multiplicação de pesquisas sobre a relação entre currículo e política.

Como se vê, os debates ainda protagonizam os vários pós contra os teóricos e as teorias críticas e suas permanências, fundadas na crença (Paraskeva, 2011) de que existe relação direta entre o que se estuda nas escolas e as desigualdades sociais (Apple, 1982). Alice Lopes (2013) contextualiza e analisa o campo, a partir dos anos 2000, apontando que os estudos críticos ainda estão em voga (Lopes, 2013, p. 13). A autora argumenta que, nos estudos curriculares brasileiros, os debates entre estudiosos críticos e pós-críticos persistem. Ela comenta a influência que as publicações, traduções e artigos de Tomaz Tadeu da Silva tiveram em estabelecer os cânones do campo. Silva, como um teórico do currículo, tradutor, editor e intelectual realmente preocupado com a política, conseguiu inclinar o campo em favor dos teóricos críticos (Lopes, 2013). Aderindo ao pós-estruturalismo, Lopes utiliza o conceito derridiano de diferença para discutir teoria de currículo e políticas curriculares.

Os debates atuais trazem marcas da forte presença da noção de habitus de Bourdieu (2003); da epistemologia do cotidiano de Michel de Certeau (1994); do paradigma da complexidade de Edgar Morin (1995); das epistemologias do oprimido, pós-coloniais e do Sul (Nunes, 2010; Santos, 2010); e das discussões tanto críticas quanto pós-modernas sobre política. Trazem mais do conceito de identidade do que de etnicidade de Stuart Hall (1998), além de importantes debates sobre espaço e tempo que reconhecem as fronteiras, seus entrelugares e hibridos de Bhabha (1998), como explora Carlos Eduardo Ferraço (Pinar, 2011). Além disso, leituras originais que desdobram a arquitetura do self de Derrida e exploram os rizomas curriculares a partir de Deleuze, bem como a ontologia de Maffesoli, estão permeando debates, nos quais Pinar também destaca a extrema sofisticação teórica presente na noção de currículo como desfiguração, de Antônio Carlos Amorim (Pinar, 2011, p. 55-69). 
Essas leituras profundamente questionadoras das referências e a criatividade em produzir múltiplos sentidos de currículo e formas de fazer pesquisa em currículo proliferam em muitas teorias nativas, enriquecendo ainda mais a nossa diversidade epistemológica (Pinar, 2011).

Afirmando o primado aprender com o Sul, Oliveira reitera o compromisso expresso por ela e por seus colegas em exceder as simplificaçôes teóricas reforçadas pela ciência, mantendo o foco na complexidade da ação (Pinar, 2011, p. 188-189) e na relação de copresença (Santos, 2010) entre pesquisador e protagonista da pesquisa (Süssekind, 2012). A singularidade dos estudos do cotidiano no Brasil, conforme enfatiza Süssekind, tem como base a discussão e o deslocamento da relação teoria-prática. Sob outra perspectiva, ou, em outras palavras, também essa singularidade pode ser entendida como distintividade, considerada por Tero Autio como um espaço pós-colonial de argumentação (apud Pinar, 2011, p. 192). E, após um ano de entrevistas com alguns teóricos brasileiros, a conclusão de Pinar sobre os estudos curriculares no campo no Brasil é de que "a pesquisa é, desse modo, indissociável da teoria que lhe origina". Pinar segue Elba de Sá Barreto ao dizer que a linha mais representativa de estudos de currículo é centrada no conhecimento escolar (Pinar, 2011).

Em trabalho recente, Oliveira (2012) aponta, brevemente, o que pode ser um entendimento do contexto atual do campo e como os estudos nosdosdos com os cotidianos em currículo se inserem nele.

Assim, os estudos atuais no campo do currículo no Brasil dialogam com diferentes campos teóricos sociais e abordagens sociológicas e filosóficas, inscrevendo-se nas diferentes tendências identificadas por Silva (1999), ou criando novas referências, como atestam muitos dos trabalhos apresentados em eventos recentes da área e publicados em livros e periódicos. Para além das possíveis classificações e enquadramentos dessas diferentes produções, essa proliferação atesta a riqueza dos debates e a relevância que o campo, em sua pluralidade de possibilidades, assume para um grupo crescente de educadores. Em pesquisa recente, Pinar (2011), ao interrogar diferentes pesquisadores brasileiros, chega a formulações ricas e interessantes a respeito desse desenvolvimento do campo no Brasil. É nesse contexto que se inscrevem as reflexões a respeito dos cotidianos das escolas e mais especificamente a noção de currículo como criação cotidiana das/nas escolas, que apontamos, resumidamente. (Oliveira, 2012, p. 81)

O que se pode perceber com relação ao desenvolvimento do campo de estudos em Currículo no Brasil - e esperamos que o leitor também perceba após a leitura deste texto - é que, mesmo quando deixa de ser majoritária, a influência das teorias críticas no campo permanece grande, talvez mesmo hegemônica, fazendo com que autores de todas as tendências e matizes dialoguem com ela compulsoriamente, mesmo que de modo subliminar. Nossa hipótese de compreensão desse fenômeno vincula-se à importância intrínseca do debate crítico para a constituição do campo no país, considerando que as tendências pós-críticas, hoje majoritárias, são, elas mesmas, majoritariamente de esquerda, vinculadas ao pensamento emancipatório 
e democrático, ou seja, de certo modo emergiram, como as novas esquerdas, das teorias críticas e da esquerda tradicional.

Isso pode ser percebido pela adesão da maior parte dos teóricos do campo do Currículo em atuação no Brasil a reflexões pautadas pelo pensamento filosófico e sociológico progressista, mas não marxista, conforme temos acompanhado no crescimento da produção do grupo de trabalho Currículo da ANPEd e dos principais grupos de pesquisa espalhados pelo país.

Para situar com mais concretude o leitor nesta parte final do texto, estamos nos referindo aos grupos foucaultiano e deleuziano que atuam na UFRGS, ao trabalho desenvolvido na Universidade Luterana do Brasil (Ulbra) com reflexão pautada nos estudos culturais, aos colegas da Unicamp, onde deleuzianos e cotidianistas se fazem presentes, e à Pontifícia Universidade Católica de São Paulo (PUC-SP), onde o pensamento freireano exibe contornos contemporâneos e sinais de permanente atualização.

No Rio de Janeiro, na UERJ, na Unirio e na UFF, diferentes grupos também discutem o pensamento progressista e de esquerda contemporâneo, em suas diversas tendências. Em Minas Gerais, como no Rio Grande do Sul, Foucault e Deleuze partilham privilegiadamente a cena, enquanto na Bahia a multirreferencialidade compartilha com a reflexão autobiográfica os principais debates no campo do Currículo. No Espírito Santo, cotidianistas deleuzianos e spinozistas atuam conjuntamente na produção principal do campo. Cabe ressaltar, ainda, que autores como Ernesto Laclau, Jacques Derrida, Boaventura de Sousa Santos, Aníbal Quijano, Walter Mignolo, Michel de Certeau, Clifford Geertz, Homi Bhabha, Antonio Negri, Richard Sennett, entre outros, todos inequivocamente de esquerda, fazem-se presentes nos grupos de diferentes tendências, evidenciando a propriedade daquilo que nossos estudos e reflexões nos levaram a afirmar neste texto.

Por outro lado, cremos que o fato das teorias críticas serem, epistemologicamente, mais próximas do pensamento moderno e de seu cientificismo, com quem dialoga sob a forma de oposições dualistas e raciocínios que opõem verdadeiro e falso, com base em regras objetivas de compreensão do mundo, as torna, também, mais palatáveis e compreensíveis, aproximando-as da lógica dos dominantes, permitindo-lhes ocupar, como oposto, o mesmo lado da linha abissal que exclui por mecanismos de invisibilização, deslocando para o outro lado da linha abissal, outras formas epistemológicas de compreensão e explicação do mundo e das questões ligadas à educação e aos currículos, mas essa discussão fica para um próximo texto.

\section{REFERÊNCIAS}

Alves, N. et al. Criar currículo no cotidiano. São Paulo: Cortez, 2001.

Alves, N.; Garcia, R. L. (Orgs.). O sentido da escola. Petrópolis: DP\&A, 2008.

Alves, N.; Oliveira, I. B. (Orgs.). Pesquisa nos/dos/com os cotidianos das escolas: sobre redes de saberes. Petrópolis: DP\&A, 2008.

Apple, M. Ideologia e currículo. São Paulo: Brasiliense, 1982. 
Baudelot, C.; Establet, R. Lécole capitaliste en France. Paris: Maspéro, 1971.

Внавна, H. O Local da Cultura. Belo Horizonte: Editora da UFMG, 1998.

Воввіо, N. Direita e esquerda: razões e significados de uma distinção política. São Paulo: Editora da UNESP, 1995.

Bourdieu, P. A economia das trocas simbólicas. 5. ed. São Paulo: Perspectiva, 2003.

Bourdieu, P.; Passeron, J. C. La reproduction. Paris: Minuit, 1971.

Bowles, S.; Gintis, H. La instrucción escolar en la América capitalista. Madri: Siglo XXI, 1981.

Certeau, M. de. A invenção do cotidiano 1: artes de fazer. Petrópolis: Vozes, 1994.

Cunha, L. A. Educaşão e desenvolvimento social no Brasil. 2. ed. Rio de Janeiro: Francisco Alves, 1977a.

. Politica educacional no Brasil: a profissionalização no ensino médio. 2. ed. Rio de Janeiro: Eldorado, 1977b.

Cury, C. R. J. Ideologia e educação brasileira: católicos e liberais. São Paulo: Cortez \& Moraes, 1978.

Ezpeleta, J.; Rockwell, E. Pesquisa participante. São Paulo: Cortez/Autores Associados, 1986.

Freire, P. Educação como prática de liberdade. 13. ed. São Paulo: Paz e Terra, 1982.

. Pedagogia do oprimido. Rio de Janeiro: Paz e Terra, 1970.

Frigotto, G. A produtividade da escola improdutiva. São Paulo: Cortez/Autores Associados, 1994.

Gadotti, M. Concepşão dialética da educação: um estudo introdutório. 5. ed. São Paulo: Cortez/Autores Associados, 1987. . Educação e compromisso. Campinas: Papirus, 1985.

. Educação e poder: introdução à pedagogia do conflito. São Paulo: Cortez/ Autores Associados, 1980.

Ginzburg, C. Mitos, Emblemas e Sinais: Morfologia e História. São Paulo: Cia. das Letras, 1989.

Goodson, I. Currículo: teoria e história. Petrópolis: Vozes, 1995.

. Currículo, narrativa e o futuro social. Revista Brasileira de Educação, Rio de Janeiro, v. 12, n. 35, p. 241-252, ago. 2007.

Habermas, J. Para a reconstrução do materialismo histórico. São Paulo: Brasiliense, 1981. Habermas, J. et al. Os Pensadores. São Paulo: Abril Cultural, 1983.

Hall, S. A identidade cultural na pós-modernidade. Rio de Janeiro: DP\&A, 1998.

Horta, J. S. B. Planejamento educacional. In: Mendes, D. T. (Coord.). Filosofia da educação no Brasil. Rio de Janeiro: Civilização Brasileira, 1983. p. 195-239.

Kumar, A. Curriculum studies in Brazil: an overview. In: Pinar, W. F.(Ed.). Curriculum studies in Brazil: intellectual histories, present circumstances. Nova York: Palgrave MacMillan, 2011. 
Lopes, A. Teorias pós-críticas, política e currículo. Educação, Sociedade e Cultura, n. 39, p. 7-23, 2013.

Lopes, A.; Macedo, E. Curriculum, policy, practice. Transnational Curriculum Inquiry, v. 8, n. 2, 2011. Disponível em: <http://ojs.library.ubc.ca/index.php/tci>. Acesso em: 14 ago. 2017.

Mello, G. N. de. Magistério de 1. ${ }^{\circ}$ grau: da competência técnica ao compromisso político. 3. ed. São Paulo: Cortez/Autores Associados, 1982.

Moreira, A. F. B. A recente produção científica sobre currículo e multiculturalismo no Brasil (1995-2000): Avanços, desafios e tensões. Revista Brasileira de Educação, n. 8, p. 65-81, 2001.

. Apresentação. Educação em Revista, n. 45, p. 109-117, 2007.

. O campo do currículo no Brasil: Construção no contexto da AnpeD. Cadernos de Pesquisa, n. 117, p. 81-101, 2002.

Moreira, A. F. B.; Garcia, R. L. (Orgs.). Currículo na contemporaneidade: incertezas e desafios. São Paulo: Cortez, 2003.

Moreira, A. F. B.; Silva, T. T. da. (Orgs.). Currículo, cultura e sociedade. São Paulo: Cortez, 1994.

Morin E . Ciência com consciência. Rio de Janeiro: Bertrand Brasil, 1995.

Nidelcoff, M. T. Uma escola para o povo. São Paulo: Brasiliense, 1978.

Nunes, J. A. O Resgate da epistemologia. In: Santos, B. S.; Meneses, M. P. (Orgs.). Epistemologias do Sul. São Paulo: Cortez, 2010.

Oliveira, I. B. Curriculo como criação cotidiana. Petrópolis/RJ: DP et Alii, 2012.

Paiva, V.; Rattner, H. Educação permanente e capitalismo tardio. São Paulo: Cortez/ Autores Associados, 1985.

Paraskeva, J. M. Conflicts in Curriculum Theory: Challenging Hegemonic Epistemologies. Nova York: Palgrave/MacMillan, 2011.

Pinar, W. F. Curriculum studies in Brazil: intellectual histories, present circumstances. New York: Palgrave Macmillan, 2011.

Pucci, B. (Org.). Teoria crítica e educação. Petrópolis: Vozes, 1994.

Rossı, W. G. Capitalismo e educação. 2. ed. São Paulo: Moraes, 1980.

Santomé, J. T. El curriculum oculto. 4. ed. Madri: Morata, 1994.

Santos, B. de S. Para além do pensamento abissal. In: Santos, B. S.; Meneses, M. P. (Orgs.). Epistemologias do Sul. São Paulo: Cortez, 2010.

Silva, T. T. da. Documentos de identidade: uma introdução às teorias do currículo. Belo Horizonte: Autêntica, 1999.

Silva, T.T. da; Moreira, A. F. B. (Orgs.). Territórios contestados: o currículo e os novos mapas culturais. Petrópolis: Vozes, 1995.

Süssekind, M. L. O ineditismo dos estudos nosdoscom os cotidianos: currículos e formação de professores, relatos e conversas em uma escola pública no Rio de Janeiro, Brasil. e-Curriculum, São Paulo, v. 9, n. 2, p.1-21, ago. 2012. 
Süssekind, M. L.; Pinar, W.F. Quem é... William F. Pinar?. Petrópolis: De Petrus, 2014. Torres, C. A. (Ed.). Education, power and personal biography. Dialogues with critical educators. Nova York/Londres: Routledge, 1998.

\section{SOBRE AS AUTORAS}

Inês Barbosa de Oliveira é doutora em Sciences Et Théories de Léducation pela Université de Sciences Humaines, de Strasbourg (França). Professora da Universidade do Estado do Rio de Janeiro (UERJ).

E-mail: inesbo2108@gmail.com

Maria Luiza Süssekind é doutora em Educação pela Universidade do Estado do Rio de Janeiro (UERJ). Professora da Universidade Federal do Estado do Rio de Janeiro (Unirio).

E-mail:1uli551@hotmail.com

Recebido em 10 de agosto de 2015 Aprovado em 17 de fevereiro de 2016 